\title{
COOPERAÇÃO ACADÊMICA E FORTALECIMENTO DA PÓS-GRADUAÇÃO EM CIDADES DO INTERIOR
}

\author{
Valdir Heitor Barzotto ${ }^{1}$ \\ Thomas Massao Fairchild ${ }^{2}$ \\ Renata Lucena Dalmaso ${ }^{3}$ \\ Aline Santos do Nascimento ${ }^{4}$ \\ Adriana Santos Batista ${ }^{5}$
}

\begin{abstract}
Resumo: Este texto tem por objetivo apresentar e problematizar algumas estratégias para a consolidação de programas de pós-graduação situados em instituições do interior. Parte-se, inicialmente, da caracterização de dois programas acadêmicos em Letras, um recém criado e outro com poucos anos de funcionamento, respectivamente, da Bahia e do Pará, para exemplificar os desafios e as possibilidades de construção de uma identidade local. Tendo em vista cursos com essas características, passa-se à discussão de possíveis estratégias para fortalecimento e enfrentamento da avaliação, tanto institucional quanto social. Por fim, problematiza-se o papel das pesquisas desenvolvidas fora dos grandes centros, sua contribuição para a produção de conhecimento e perspectivas de cooperação acadêmica nacional e internacional.
\end{abstract}

Palavras-chave: Avaliação institucional; Formação de pesquisadores; Internacionalização.

\section{Contextualização}

A escrita deste texto resulta das discussões ocorridas na mesa promovida em maio de 2020, no Congresso Virtual da Universidade Federal da Bahia (UFBA), intitulada Cooperação acadêmica e fortalecimento da pós-graduação em cidades do interior ${ }^{6}$. Embora a motivação inicial para sua realização tenha sido a aprovação de um programa de pós-graduação em Letras na Universidade do Estado da Bahia (UNEB), situado no campus de Teixeira de Freitas, e possibilidades de fortalecimento, as discussões

\footnotetext{
${ }^{1}$ Professor titular da Faculdade de Educação, da Universidade de São Paulo (USP). Docente do Programa de Pós-Graduação em Educação e do Programa de Pós-Graduação em Filologia e Língua Portuguesa, ambos da USP. ${ }^{2}$ Professor da Universidade Federal do Pará (UFPA), docente do Programa de Pós-Graduação em Letras da UFPA. ${ }^{3}$ Professora da Universidade Federal do Sul e Sudeste do Pará (Unifesspa), campus de Marabá, docente do Programa de Pós-Graduação em Letras da Unifesspa.

${ }^{4}$ Professora da Universidade do Estado da Bahia (UNEB), campus de Teixeira de Freitas, docente do Programa de Pós-Graduação em Letras da UNEB.

${ }^{5}$ Professora da Universidade Federal da Bahia (UFBA), docente do ProfLetras (rede nacional) e do Programa de Pós-Graduação em Língua e Cultura da UFBA.

${ }^{6}$ Texto escrito a partir da transcrição da mesa Cooperação acadêmica e fortalecimento da pós-graduação em cidades do interior, realizada por Tailana Celina Braz Botelho e Windson da Silva Santos.
} 
estabelecidas acabaram por ultrapassar as especificidades, tanto de programas de Letras, quanto daqueles situados no interior, tornando-se exemplares para instituições de ensino com demandas similares, que podem conhecer as principais estratégias de trabalho aqui mencionadas.

Nos posicionamentos apresentados, convergiram reflexões e encaminhamentos que indicam caminhos para se refletir sobre a sustentação de programas de pós-graduação para além das avaliações oficiais efetuadas pela Coordenação de Aperfeiçoamento de Pessoal de Nível Superior (CAPES). Assim, ao apontamento em um único texto dos aspectos debatidos, subjaz a percepção de que as exposições compõem um todo cujo registro tem a contribuir para o debate sobre os caminhos da pós-graduação no Brasil.

Aqui cabe retomar algumas palavras do prefácio de Sem choro nem vela: cartas aos professores que ainda vão nascer (RIOLFI; BARZOTTO, 2012), livro voltado à reflexão sobre caminhos para a formação de docente: "Trata-se de trabalhar para que as instituições universitárias que se dedicam à pesquisa colaborem para a superação dos impasses que têm impactos sobre a formação das novas gerações e se oponham à distribuição e ao reforço de reclamações.” (p. 10). Se no livro buscava-se o diálogo com professores e seus formadores, aqui incluem-se aqueles que, de diferentes instâncias, vinculam-se a programas de pós-graduação, principalmente em Letras, ou almejam vincular-se. A perspectiva do nascimento, presente no título do livro citado, diz respeito, não somente ao surgimento, mas às diferentes concepções do que seja um programa, transformadas à medida em que outros sujeitos, espaços e práticas integram-se e são integrados.

Inicialmente, são discutidas características e desafios inerentes à construção de novos programas de pós-graduação em Letras no interior a partir de experiências da Universidade Federal do Sul e Sudeste do Pará (Unifesspa) e da UNEB. Em seguida, apresentam-se algumas possibilidades de fortalecimento e superação dos desafios da avaliação, tanto a social quanto a institucional. Por fim, há uma problematização sobre as relações centro versus periferia, inerentes à expansão do sistema de pós-graduação no Brasil; reflexão que incide nos modos de estruturação e possibilidades de constituição.

\section{Sobre o nascimento de programas de pós-graduação}

As duas experiências de jovens programas em cidades do interior relatadas a seguir dizem respeito a um vinculado à UNIFESSPA, campus de Marabá, e outro da UNEB, campus de Teixeira de Freitas, ambos nomeados como Programa de Pós-Graduação em Letras, respectivamente Poslet e PPGL. O primeiro iniciou suas atividades em 2017, ao passo que o segundo teve aprovação pela CAPES em 2020, ainda com início das atividades previsto para 2021. 


\subsection{Em Marabá (PA), Poslet da Unifesspa}

Marabá é uma cidade do Pará com 279.349 habitantes (BRASIL, 2019). Trata-se de um polo regional que fica a 530 quilômetros de Belém. Em função do modo como se constituíram as Universidades no Brasil, privilegiando as capitais, por muito anos Marabá contou apenas com um campus da Universidade Federal do Pará (UFPA) e com baixíssimo investimento em pós-graduação. Antes da criação do Poslet, a Unifesspa (fundada em 2013 a partir do desmembramento da UFPA) contava com o Mestrado Profissional em Letras (ProfLetras), sob coordenação geral da Universidade Federal do Rio Grande do Norte.

Assim como a experiência acumulada pelo programa já existente foi fundamental para a construção da proposta de mestrado acadêmico, o aprendizado inerente à tarefa de coordenação é determinante para o sucesso de um programa que está nascendo. Nesse sentido, a permanência da equipe constitui-se como cenário ideal, fator que garante a continuidade das estratégias de médio e longo prazo.

Com relação ao perfil discente, em sua maioria são pessoas da região que atuam na educação básica e buscam se aperfeiçoar profissionalmente; não raro, há os que se formaram há muito tempo e se mantiveram afastados da universidade. O perfil do egresso é, em linhas gerais, de alguém que vai continuar na região trabalhando com educação. A grande demanda pela formação se evidencia com os dados da última seleção, por exemplo, ocorrida em 2019, em que houve noventa e seis inscritos e dezesseis aprovados. A presença de um programa de pós-graduação stricto sensu acadêmico tem alterado, inclusive, a perspectiva dos alunos de graduação da instituição, posto que o acompanhamento das atividades do mestrado lhes permite vislumbrar possibilidades de prosseguimento dos estudos.

Aliada a essa vivência que a proximidade com o programa permite, há a necessidade de preparar os que almejam ingressar como alunos em dinâmicas próprias da pós-graduação, com a realização de seminários e workshops, por exemplo. A proximidade do futuro candidato com essas práticas, para além de se propiciar diferentes atividades de extensão, conduz paulatinamente à compreensão do que é esperado em uma prova de proficiência, projeto e entrevista. As seleções ocorridas desde o início do programa têm mostrado que é necessário investir na preparação do candidato de modo que a burocracia inerente ao processo não seja o maior entrave para a aprovação.

Um dos pontos positivos de programas pequenos e que estão se estruturando diz respeito à possibilidade de se construírem laços mais fortes entre as pessoas, as relações criadas são determinantes para o bom andamento das atividades. É possível criar uma comunidade de discentes, docentes e técnicos em que as pessoas se conhecem; realidade muito distante de ser alcançada em programas de grande porte. Desse modo, o que poderia ser um entrave acaba por se tornar uma possibilidade de fortalecimento frente às demandas e exigências oficiais.

Construir uma relação com a comunidade, portanto, não somente a acadêmica, é fundamental, posto que as tarefas a serem desenvolvidas podem demandar muito 
esforço, tanto pela falta de experiência, quanto de recursos. Não se pode perder de vista algo bastante comum em programas, recentes ou não, de instituições situadas fora dos grandes centros, que diz respeito à disponibilidade de infraestrutura e recursos humanos. Frente a esse cenário, faz-se necessário trabalhar da melhor forma possível com os recursos disponíveis, encontrando soluções criativas dentro das possibilidades. Em um contexto de diminuição de investimentos, a busca constante por essas soluções constitui-se como pré-requisito para quem espera ter sucesso com um programa do interior.

Ainda sobre a escassez de recursos, dificilmente os alunos participam de congressos distantes, em outras cidades ou estados; tais atividades costumam ser restritas aos que ocorrem na própria região, organizados pela própria universidade. Algo que costuma ser discutido entre os docentes é que, nesse cenário de escassez crescente de recursos, há que se investir nas opções viáveis, dentre as quais incluem-se as publicações.

No que concerne às características definidoras do programa, destaca-se o potencial inovador para pesquisas na região. Sua identidade liga-se diretamente às características das populações do entorno, dentre as quais há indígenas, quilombolas e ribeirinhos. Se pesquisadores de outras instituições valem-se dessa diversidade em suas pesquisas, o próprio programa pode articular-se para que os projetos e pesquisas dialoguem com o espaço em que ele se insere. Tal integração é vista, por exemplo, nas defesas, que têm ocorrido em espaços externos à universidade, como aldeias, terreiros ou sindicatos.

Dentre as ações para o fortalecimento, destacam-se as parcerias via editais, cada vez menos frequentes. Um deles é o Programa Nacional de Cooperação Acadêmica na Amazônia (PROCAD/Amazônia), lançado em 2018 pela CAPES, cujo objetivo é auxiliar programas de pós-graduações nota três no norte do país, de modo a articulá-los a outros programas com nota cinco e sete do sul e sudeste. Por meio dele, firmou-se uma parceria entre o Poslet e programas da Universidade Federal do Rio Grande do Sul e da Universidade Federal do Tocantins, que tem propiciado a realização de algumas ações.

Cabe ainda observar que o distanciamento social imposto pela pandemia tem obrigado a reflexão sobre novas maneiras de interagir academicamente. No caso do Poslet, do qual várias dificuldades advêm justamente do isolamento geográfico, poder participar de eventos com pessoas do Brasil inteiro e dos outros países caracteriza-se como uma oportunidade de aprendizado que provavelmente será incorporada posteriormente. Esse período também tem sido utilizado para a reorganização de aspectos concernentes à visibilidade, como site e redes sociais. Para ações desse tipo, é fundamental a parceria, principalmente com os discentes, que têm contribuído com planejamento e divulgação. São ações que, se bem articuladas, têm o potencial de chegarem aos próximos candidatos. 


\subsection{Em Teixeira de Freitas (BA), PPGL da UNEB}

No caso do PPGL da UNEB, situado no campus de Teixeira de Freitas, existe uma demanda muito grande na região do Extremo Sul da Bahia para formação em nível de pós-graduação stricto sensu em Letras, posto que a graduação em Letras já existe na cidade há mais de 30 anos. Todos que tiveram sua formação inicial na região e hoje possuem pós-graduação stricto sensu tiveram de fazer longos deslocamentos. Tal situação implica em barreiras, principalmente financeiras, para se manter em um curso de pós-graduação distante do local de residência.

A exemplo dos moradores de Marabá, os de Teixeira de Freitas, município com 160.487 habitantes (BRASIL, 2019), permaneceram afastados da oferta de programas de pós-graduação, no caso, da área de Linguística e Literatura. Os campi da UNEB que têm programas nessa área, como Alagoinhas e Salvador, ficam, respectivamente, a 771 e 808 quilômetros. Quanto a outras IES, há a Universidade Federal do Espírito Santo, em Vitória, que fica a 360 quilômetros de Teixeira de Freitas; a Universidade Estadual de Santa Cruz, em Ilhéus, distante 400 quilômetros; e a Universidade Federal de Minas Gerais, em Belo Horizonte, situada a 700 quilômetros. Assim, todos os professores do recém aprovado programa da UNEB que se graduaram no campus de Teixeira de Freitas cursaram mestrado e doutorado em cidades distantes de sua residência.

A proposta geral do curso tem Letras como grande área de conhecimento, e como linhas de pesquisa os estudos de Linguística e os estudos de Literatura. Isso se configura como algo semelhante aos demais programas da área, mas o PPGL almeja um diferencial, na tentativa de se aprofundar em especificidades da região. Tem-se como pressuposto que, além de pesquisadores de outras instituições que estudam temas locais, pessoas formadas na região têm o potencial de refletir sobre as características linguísticas e culturais constitutivas, sobre sua identidade.

A título de exemplo, o território de identidade do extremo sul da Bahia apresenta diversas linhas de interesse para pesquisas ligadas às comunidades indígenas. Neste território, estão pessoas que são cientes da sua importância, da necessidade de se conhecer e de levar o conhecimento sobre a sua cultura para outros espaços. Há também diversas comunidades quilombolas na região, cada uma com suas especificidades, como manifestações artísticas e festividades.

Ressalta-se também a produção literária local, bem como uma produção crítica, que pode colaborar para a composição de um estado da arte que se pretende organizar pelos integrantes do programa. Pode ser citado o exemplo de Helvécia, comunidade quilombola localizada em Nova Viçosa, no entorno de Teixeira de Freitas, sobre a qual já existem estudos acadêmicos produzidos, por discentes e docentes da área de Educação, História e Letras.

Algumas dessas pesquisas compuseram a proposta do curso, que se inicia com o mestrado, como a do professor Gean Paulo Santana, intitulada "Vozes e versos afro-latinos: uma poética identitária de resistência” (SANTANA, 2014), na qual ele estuda também a comunidade de Helvécia. Um outro destaque seria a pesquisa 
desenvolvida pela professora Crysna Bonjardim Carmo, no intuito de construir o mapa linguístico da fala espontânea do Extremo Sul da Bahia (CARMO, 2020).

Desse modo, apesar de ter seu nascimento anunciado durante a pandemia da Covid-19, espera-se que o Programa possa ser implantado o quanto antes e possa ser consolidado formando turmas de pesquisadores na área de Letras e contribuindo principalmente para o desenvolvimento e o fortalecimento dos bens culturais da região. O PPGL pretende colaborar para a produção de conhecimento em Linguística e Literatura, que, por sua vez, enriquece a criticidade daqueles que estão envolvidos em seu processo.

\section{Estratégias para fortalecimento e enfrentamento da avaliação}

Uma primeira tarefa para fortalecer um programa de pós-graduação no interior é pensar a sua inserção na sociedade local. É preciso dizer que o momento de aprovação de um programa é extremamente delicado, o corpo docente e discente precisa ser muito articulado para fazer frente a este momento de suspensão de recursos e suspeição das ciências. Por esse motivo, é fundamental estabelecer diálogo com a região em que se insere. Em se tratando de um mestrado acadêmico em Letras, interessa, principalmente, o diálogo com os professores de Língua Portuguesa, alunos de Letras e alunos do ensino médio.

Para programas em fase inicial, é importante compreender como os professores da educação básica recebem a notícia sobre existência do mestrado e quais são suas expectativas. Quanto aos alunos de graduação em Letras, pode-se buscar saber o que significa para eles a existência do programa, se eles têm clareza sobre a possibilidade de continuidade dos estudos, se conhecem minimamente o currículo e sabem o que é uma pós-graduação. No caso dos alunos do ensino médio, é possível buscar junto a eles a compreensão do que representa a possibilidade de fazer Letras e, posteriormente, o mestrado.

Uma estratégia para dialogar com esses três grupos pode ser, por exemplo, a realização de questionários de pesquisa. Por meio desse recurso, além dos próprios dados resultantes da pesquisa, promove-se o curso e criam-se formas de aproximação com contatos para futuros convites para palestras, eventos, etc.

Há ainda um quarto grupo com o qual se pode estabelecer forte cooperação, trata-se dos mestres e doutores da região e que não estão diretamente vinculados ao programa de pós-graduação. Para tanto, é necessário saber quem são, quais pesquisas fizeram, onde atuam, em quais áreas estão inseridos, quais desafios enfrentaram para se formarem. A criação de um espaço de fala para esses pesquisadores, no interior dos programas, para que eles apresentem um pouco do seu memorial, caracteriza-se como estratégia para valorização da estrutura estabelecida. Após algum tempo de criação, a não existência do programa tende a deixar a memória coletiva, por isso é importante a apresentação da memória desses profissionais. 
Ao conhecer esses mestres e doutores da região, pode-se iniciar uma grande pesquisa a respeito do que já foi produzido por membros da comunidade para que vá se compondo um acervo a respeito das pesquisas já feitas. Tal tarefa pode se concretizar, por exemplo, com a criação de um projeto coletivo de pesquisa em que se reúna o estado da arte da pesquisa em estudos da linguagem na região.

Para projetos dessa natureza, os principais passos são: a reunião dos estados da arte já feitos individualmente ou em pequenos grupos de pesquisa; o mapeamento do que foi produzido por moradores ou trabalhadores da região, que fizeram estudos sobre qualquer tema relacionado à região, ou simplesmente sobre temas não ligados à localidade, mas feitos por profissionais locais. Abre-se também a possibilidade de convidar essas pessoas para realizarem depoimentos junto ao programa, de modo que as gravações desses materiais possam compor o acervo de conhecimento sobre a região.

Uma outra etapa constitui-se no mapeamento do que foi produzido sobre a região por pesquisadores de outras regiões. Ainda uma outra possibilidade de trabalho seria observar de que maneira essas pesquisas feitas por pesquisadores locais repercutem em outros lugares. A construção coletiva de um banco de dados com o estado da arte garante ao aluno de pós-graduação a possibilidade de consultá-lo para sua pesquisa, além de propiciar o trabalho coletivo de criação desse instrumento. Isso pode ser feito de modo organizado, de maneira que, com o passar do tempo, seja possível dar visibilidade ao trabalho realizado e haja um vínculo de fato com essa sociedade que cerca o programa.

Tem sido frequente, em dissertações e teses, a citação a estados da arte já realizados, em detrimento de uma nova construção. No caso de cursos que estão se estruturando, é importante que cada estado da arte feito contribua para a construção coletiva de um banco de dados, para que ele não seja simplesmente citado, mas problematizado e aprofundado a cada período de pesquisa que se vai fazendo.

Tudo isso diz respeito aos processos de avaliação, que podem ser divididos em avaliação social e avaliação institucional. O primeiro tipo relaciona-se ao que foi exposto anteriormente, sobre a necessidade de diálogos com os professores, alunos de Letras e estudantes do ensino médio; pois é bastante prejudicial ao programa que os estudantes de graduação não saibam da possibilidade de prosseguir os estudos na própria região. Do mesmo modo, não é adequado que a concorrência no vestibular seja baixa, que os alunos do ensino médio não conheçam a possibilidade de fazer uma formação de longa duração perto de suas residências e que os professores de português não tenham no mestrado uma possibilidade de buscar novos conhecimentos, aprofundamentos para melhorar a sua própria prática. Há situações em que um programa tem uma boa nota de acordo com a CAPES, mas não é bem visto na comunidade, tal aspecto não pode ser desconsiderado.

Faz-se necessário também cuidar de uma certa geopolítica acadêmica para que um programa novo se firme no meio acadêmico. As publicações decorrentes, por exemplo, não podem somente reproduzir temas e bibliografias que outros 
programas já utilizam; elas precisam apresentar novos objetos para análise, cruzar bibliografia que já está sendo usada no país com bibliografia nova. Isso vai evidenciar um caráter inusitado das pesquisas desenvolvidas.

É preciso que as pessoas que constroem um programa não se atenham somente aos elementos explícitos nas avaliações oficiais, pois há um conjunto bem grande de fatores que não são explicitados por serem óbvios. Tais fatores têm peso na comunidade acadêmica e na sociedade, e, embora não sejam enunciados, eles podem influenciar também as avaliações feitas pelos órgãos oficiais. A título de exemplo, os pareceres a revistas acadêmicas não contam muitos pontos no currículo, nem nas avaliações da CAPES, mas pode soar estranho que, no currículo de um professor que integra o corpo docente de um programa de pós-graduação, não haja menção a nenhum parecer para revistas. Portanto, pensar numa avaliação a longo prazo implica considerar as atividades que a cultura acadêmica impõe como obrigatórias, mesmo as não explicitadas.

\section{Relação centro X periferia}

Pode parecer paradoxal que, nas últimas décadas, o Brasil tenha conseguido promover uma expansão mais ou menos contínua do seu sistema de pós-graduação, processo que está sendo abruptamente interrompido. Apesar disso, chegou-se a constituir um sistema de educação pós-graduada robusto, regulamentado e, em certo sentido, também participativo. Quando se olha para os dados que a CAPES apresenta sobre a área de Linguística e Literatura, talvez o último documento de área desse período de expansão, os dados apresentados indicam uma ambivalência.

Se, de um lado, eles mostram um avanço inegável da pós-graduação no Brasil, de outro, eles indicam um quadro de desigualdade muito expressivo. Segundo o documento de área de 2019 (CAPES, 2019), de 2000 a 2018 passou-se de sessenta e seis programas acadêmicos na área de Linguística e Literatura para cento e cinquenta e quatro. $O$ documento também aponta que essa expansão tem resultado em uma redução de desigualdades regionais, inclusive por meio de uma interiorização da pós-graduação. Essa expansão merece reconhecimento, mas é preciso observar também que, a despeito dela, as desigualdades ainda são grandes: em 2019, a região sudeste concentrava 42\% dos programas na área existentes no país.

Além dos aspectos numéricos, é necessário compreender as concepções que subjazem a essa política da CAPES. Com relação à política para redução das desigualdades regionais, o que está e jogo não são apenas a criação e a distribuição geográfica dos programas, mas também uma distribuição de papéis que se conferem aos diferentes programas e às diferentes regiões. Não se pode esquecer que o papel da CAPES não é apenas regulador, mas também estratificador, de modo que são atribuídas funções distintas aos programas, conforme a nota que eles têm. As consequências dessa estratificação de papéis podem ser problemáticas. 
Citamos aqui um exemplo vivido por um de nós. Em um congresso internacional ocorrido alguns anos atrás, durante as palestras, observou-se que por vezes as pessoas começavam a cochichar por conta de dificuldades para acompanhar as falas feitas em língua estrangeira. Um comentário entreouvido nesse contexto merece destaque: um grupo de alunos não estava conseguindo entender uma palavra que o palestrante repetia o tempo todo. A palavra era "literacidad". Esse grupo de alunos tentava entender do que se tratava, achavam que tinha a ver com literatura, até que chegou alguém e esclareceu: “quando ele fala 'literacidad', ele está falando, na verdade, de “letramento'”. A partir daí o incômodo do grupo acabou, eles pararam de cochichar e continuaram escutando a palestra.

Esta cena ilustra um sentido muito peculiar que a ideia de internacionalização pode assumir. Há um consenso em nossa cultura segundo o qual nós já reconhecemos que o mundo é um lugar marcado pelas diferenças. Mas este consenso, que agora está em franca desconstrução, leva a desejar que, quando se aceitam as diferenças, necessariamente, os sujeitos se tornem iguais. Assim, aceitam-se línguas e culturas diferentes, contanto que se fale a mesma coisa. Esse é o primeiro passo para que uma língua se torne dispensável em favor de outra: que ela só sirva para dizer a mesma coisa que é dita com a outra. Tal processo de homogeneização é também um processo de diferenciação na medida em que ele funciona sempre com uma direcionalidade bem definida. Ele irradia a partir de um elemento que se comporta como "centro" na direção de outro que é tratado como "periferia".

O exemplo a respeito das línguas de ciência, línguas usadas em um congresso, vale também para os seus usuários, que são os pesquisadores falantes dessas línguas. Nesse aspecto deve-se lembrar que, em um contexto internacional, o português é a língua do interior. Isso significa que, quanto mais se integra ao "resto do mundo”, maior é a pressão, tanto para usar os idiomas já reconhecidos como línguas de ciência, quanto para dizer, com as pesquisas que se realiza, o mesmo que já está sendo dito em outros lugares. Quando se aceita essa premissa, o pesquisador situado na "periferia", talvez sem perceber, se coloca como prioridade na fila do corte. Esse parece ser o grande risco que a ciência brasileira corre hoje face aos demais países "produtores de conhecimento": o de ser encarada como dispensável, o de não conseguir deixar claro qual é sua contribuição específica para ciência do mundo. Internamente ao país acontece uma dinâmica semelhante entre as instituições universitárias.

Trata-se de um modelo de interiorização ou de internacionalização baseado na ideia de irradiação, de capilarização. Nessa perspectiva, a pesquisa avança para o interior como ramificação do trabalho realizado em um centro irradiador. Basta observar o modo como a palavra "consolidado" aparece no documento da área em muitos lugares para se referir ao papel dos programas que têm uma avaliação mais alta. O fluxo dessa expansão da pesquisa vai daquilo que é sólido em direção ao que está se solidificando, o que está em consolidação, sendo moldado. Essa lógica do tipo centro versus periferia tem seus graus diferentes: o que se constitui como 
centro pode ser a sede da universidade na capital, pode ser uma universidade de maior prestígio dentro do país, pode ser uma instituição de pesquisa estrangeira tomada como referência. Dessa forma, as políticas de redução das desigualdades regionais andam de mãos dadas com as políticas de internacionalização.

Esse modelo de interiorização, de expansão como irradiação, pauta-se em uma forma muito específica de divisão do trabalho intelectual: o que é constituído como interior ou periferia é incorporado ao circuito da pesquisa ora como mercado consumidor, ora como reservatório de dados. Desse modo, é no interior que estão os compradores da última publicação de tal ou qual autor, da nova coleção que vai ser lançada com os clássicos da Linguística, por exemplo. Chegar ao interior pode ser uma maneira de constituir um mercado para consumir a produção oriunda de outros lugares - inclusive aquela que já não é mais tão prestigiada no lugar de origem. É também no interior que podem estar os grandes reservatórios de dados: as línguas indígenas, os quilombos, as culturas populares, os extremos das contradições sociais e assim por diante.

$\mathrm{O}$ acesso a esses dois repositórios, de consumidores e de dados em potencial, mostra que é lucrativo para o "centro" expandir-se rumo às "periferias". A questão consiste em compreender o papel que se atribui aos pesquisadores locais no interior desse movimento. Quem recebe os maiores benefícios do "processamento" dessa matéria prima, que é a transformação do dado bruto das realidades locais em conhecimento? Onde se publica? Quem é citado para se falar sobre isso? Quem é chamado para falar sobre o tema nos grandes congressos internacionais? Onde acontecem os debates que fundamentam as decisões que impactam esse local? Onde se acumula o prestígio?

Se a "periferia" é integrada à pesquisa nessas condições, os “centros”, já consolidados, mantêm uma capacidade que é de ditar para sua região, para seu país ou para o mundo uma agenda de pesquisa. Ao mesmo tempo, por estar se voltando para tudo, submetendo tudo ao seu olhar, o centro se torna, ele mesmo, invisível. Ou seja, as instituições ou grupos que se apresentam como centros irradiadores se põem em uma posição na qual parecem isentos de serem submetidos aos mesmos questionamentos que se levantam sobre o que pesquisam.

Tomamos um segundo exemplo. O contexto é um programa de pós-graduação que, embora esteja situado em uma capital, é integralmente composto por docentes cuja formação em nível de doutorado se deu em outras instituições, no país e no exterior. Trata-se de um programa que ocupa as duas posições, funcionando como centro e periferia ao mesmo tempo. Nas reuniões de autoavaliação deste programa, frequentemente se aponta que uma fraqueza nas avaliações seria a vinculação das teses e dissertações com os projetos desenvolvidos pelo corpo docente. Essa percepção se traduz em um dispositivo muito específico: os exames de seleção passaram a incluir um critério que é "adequação do projeto de pesquisa do candidato ao projeto do orientador pretendido". 
Este critério de avaliação questiona o candidato em sua capacidade de desenvolver uma pesquisa adequada ao corpo docente instalado. Mas esse questionamento nos força a aceitar, de antemão, que o corpo docente do programa está isento de qualquer questionamento sobre sua capacidade de adequar-se às demandas locais. Cabe questionar se a lógica não poderia ser oposta, de tal modo que o corpo docente fosse questionado em sua capacidade ou disposição para atender aos projetos que emanam da realidade em que se insere. Isto serve para dizer que se faz necessário ao programa construir uma escuta não somente da instância que o avalia institucionalmente, mas também da comunidade para a qual ele se constitui.

Essa postura pode ser ainda mais problemática porque, se os docentes do programa tiverem se formado em outras universidades e apenas aceitarem orientar projetos que deem continuidade ao seu, isso significa que o programa do interior está fadado a ser para sempre uma espécie de sucursal dos programas que formaram sua primeira geração de professores. Um dos efeitos disso é a desarticulação interna do corpo docente, que pode encontrar dificuldade para construir uma identidade coletiva, na medida em que cada um se mantenha mais em contato com o lugar onde se formou do que com os colegas de programa ou os alunos que se formam nele.

Como alternativa a esse modelo, é possível pensar nas relações entre os professores, pesquisadores, instituições, países que mantenham a autonomia local para se estabelecer uma agenda de pesquisa própria. Isso não implica um conflito necessário com as políticas de internacionalização vigentes, nem mesmo com a existência de uma avaliação institucional em escala nacional. Também não significa negar que existam diferenças entre os programas, de qualificação ou mesmo de papéis exercidos dentro de uma articulação. Entretanto, é fundamental que, reconhecendo essas diferenças, as propostas de parceria estabeleçam um horizonte para sua superação: não se trata de incluir a "periferia” no sistema de pós-graduação, mas de multiplicar e de tornar mais difuso aquilo que se constitui como centro.

Dessa forma, toda cooperação implica ter em vista também um momento de saída, um ponto de corte em que os pesquisadores dos programas menos experientes vão assumir sua responsabilidade de caminhar com as próprias pernas. Esse horizonte precisa estar em todo projeto de articulação, de cooperação interinstitucional, ele é o cerne do que deveriam ser as nossas políticas de interiorização e internacionalização.

\section{Considerações finais}

Buscando trazer uma abordagem diferente da presente em textos oficiais, que normalmente contêm instruções e orientações para criação e avaliação de programas de pós-graduação, as discussões aqui apresentadas colocaram em destaque questões inerentes aos programas que, fora dos grandes centros, precisam superar obstáculos bastante específicos para seu fortalecimento. Entre os obstáculos a serem superados, está o de "ser posto na periferia". O principal desafio 
desses programas é o de tornar-se centro de pesquisa em algum tema, centro de um trabalho diferenciado em algum dos processos relacionados à pós-graduação. Assim, tanto a comunidade composta pelos moradores da região, quanto a comunidade acadêmica podem passar a fazer um movimento para o programa e não para fora dele.

Ao analisar o caso do Poslet em Marabá, foi possível constatar que o mesmo deve seu fortalecimento, principalmente, ao envolvimento da comunidade e às parcerias concretizadas a partir de editais, além do diferencial que o programa possui, pelo destaque dados às identidades locais, envolvendo indígenas, quilombolas e ribeirinhos. Em Teixeira de Freitas, o PPGL planeja oferecer disciplinas, bem como desenvolver pesquisas em Linguística e Literatura que possam abranger, dentre outros temas, características constitutivas de suas especificidades.

Em um momento de escassez de recursos e pouca perspectiva de investimentos na formação em nível de pós-graduação, o trabalho em torno da construção coletiva de uma identidade e sua vinculação com a região são não somente estratégias para consolidar o programa junto às comunidades local e científica, mas, principalmente, modos de existência que lhe conferem força para fazer frente aos desafios das várias avaliações pelas quais terá de passar.

\title{
ACADEMIC COOPERATION AND STRENGTHENING OF POSTGRADUATE COURSES IN COUNTRYSIDE CITIES
}

\begin{abstract}
This text aims to present and contextualize strategies to the consolidation of postgraduate programs based in institutions in the countryside. It departs, initially, from the characterization of two Letters programs, one that was recently created and another one that is also relatively young, from Bahia and Para states in Brazil, respectively, to exemplify the challenges and the possibilities of constructing a local identity. Thinking about courses that share these aspects, the text moves to a discussion of possible strategies to solidify these programs, facing the evaluation process, both socially and institutionally. Finally, the article problematizes the role of research developed outside of large urban and academic centers, its contribution to the production of knowledge, and perspectives of national and international cooperation.
\end{abstract}

Keywords: Institutional evaluation; formation of researchers; Internationalization.

\section{Referências}

BRASIL, IBGE - Instituto Brasileiro de Geografia e Estatística. População estimada, 2019. Disponível em: https://www.ibge.gov.br/cidades-e-estados. Acesso em: 20 maio 2020.

CARMO, Crysna Bonjardim da Silva. Corpus de Migração: Um estudo da variação dos segmentos [t, d e s] na fala espontânea de Teixeira de Freitas. Linguagem em (Re)vista, v. 15, n. 29, Niterói, 2020. 
COORDENAÇÃO DE APERFEIÇOAMENTO DE PESSOAL DE NÍVEL SUPERIOR. Documento de área Linguística e Literatura. 2019. Disponível em: http://www. uab.capes.gov.br/images/Documento_de_\%C3\%A1rea_2019/Linguistica_e_ Literatura.pdf. Acesso em: 20 maio 2020.

RIOLFI, Claudia Rosa; BARZOTTO, Valdir Heitor. Sem choro nem vela: carta aos professores que ainda vão nascer. São Paulo: Paulistana, 2012.

SANTANA, Gean Paulo Gonçalves. Vozes e versos quilombolas: uma poética identitária e de resistência em Helvécia. Revista da FAEEBA - Educação e Contemporaneidade, Salvador, v. 23, n. 42, jul./dez. 2014. 